\title{
EXTENSÃO DA DISTRIBUIÇÃO DE TRÊS ESPÉCIES DE CAMARÕES DO GÊNERO SYNALPHEUS SPENCE BATE, 1888 (DECAPODA: ALPHEIDAE) NO ATLÂNTICO SUL OCIDENTAL
}

\author{
Paixão, P.H. ${ }^{1,}$; Santos, P.S. ${ }^{1}$; Soledade, G.O. ${ }^{1}$ \& Almeida, A.O. ${ }^{1}$ \\ ${ }^{1}$ Universidade Federal de Pernambuco (UFPE), Campus Recife, Laboratório de Biologia de Crustáceos. \\ *Autor correspondente: phpsilva2111@gmail.com
}

\begin{abstract}
Synalpheus é o segundo gênero mais diverso da família Alpheidae, apresentando 169 espécies distribuídas pelo mundo, sendo muitas encontradas em associação com esponjas. No Atlântico Ocidental, a maioria dos estudos envolvendo estes camarões foi conduzida em sua porção norte, no Mar do Caribe, enquanto que, no Brasil, poucos estudos foram realizados, incluindo novos relatos de ocorrência. O objetivo deste trabalho foi registrar três novas ocorrências do gênero no litoral pernambucano que aumentam a distribuição conhecida para as espécies. Foram efetuadas dragagens na plataforma continental ao largo de Recife em fevereiro de 2018, em profundidades de 50 a $65 \mathrm{~m}$. As esponjas coletadas foram cuidadosamente fragmentadas e os alfeídeos obtidos foram separados, preservados em álcool $70 \%$, devidamente etiquetados e identificados com base em chaves de identificação e descrições originais. Foi registrada a ocorrência de Synalpheus yano ( $\mathrm{n}=1$, em 8 ${ }^{\circ} 13^{\prime} 52.1^{\prime \prime}$ S $34^{\circ} 37^{\prime} 41.2^{\prime \prime}$ W), presente, no extremo norte, no Golfo do México e previamente relatado, no Brasil, apenas para o estado do Ceará, aumentando assim sua distribuição meridional. Esta espécie havia sido previamente observada em associação com esponjas em profundidades de 10 a 15 m. Esta distribuição batimétrica é agora estendida para 51,8 metros. Duas outras espécies, ambas simbiontes de esponjas, eram previamente conhecidas apenas de suas localidades-tipo e constituem novas ocorrências para a costa brasileira e para o Atlântico Sul Ocidental. Synalpheus cf. brevidactylus ( $\mathrm{n}=1$, em $8^{\circ} 13^{\prime} 52.1^{\prime \prime} \mathrm{S} 34^{\circ} 37^{\prime} 42.7^{\prime \prime} \mathrm{W}$ ), localidade-tipo Isla Grande e Bocas del Toro, Panamá, era conhecida em profundidades de 1 a $3 \mathrm{~m}$, tendo sido coletada em $50 \mathrm{~m}$ no presente estudo. Synalpheus corallinus ( $\mathrm{n}=2$, em $8^{\circ} 13^{\prime} 33.0^{\prime \prime} S 34^{\circ} 37,40.3 » W$ ), localidade-tipo Discovery Bay, Jamaica, não possuía dados a respeito da profundidade onde vive, e foi encontrada a 51,8 metros no presente estudo.
\end{abstract}

Palavras-chave: Crustacea, Caridea, novos registros, biodiversidade.

Financiamento: FACEPE, CNPq, CAPES. 